\title{
Joseph Jurt, Flaubert et les arts visuels
}

\section{Maria Emanuela Raffi}

\section{(2) OpenEdition}

\section{Journals}

\section{Edizione digitale}

URL: https://journals.openedition.org/studifrancesi/4758

DOI: $10.4000 /$ studifrancesi.4758

ISSN: 2421-5856

\section{Editore}

Rosenberg \& Sellier

\section{Edizione cartacea}

Data di pubblicazione: 1 avril 2012

Paginazione: 172-173

ISSN: 0039-2944

\section{Notizia bibliografica digitale}

Maria Emanuela Raffi, «Joseph Jurt, Flaubert et les arts visuels», Studi Francesi [Online], 166 (I | LVI) |

2012, online dal 30 novembre 2015, consultato il 19 novembre 2021. URL: http://

journals.openedition.org/studifrancesi/4758 ; DOI: https://doi.org/10.4000/studifrancesi.4758

Questo documento è stato generato automaticamente il 19 novembre 2021.

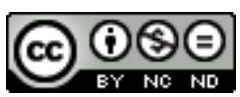

Studi Francesi è distribuita con Licenza Creative Commons Attribuzione - Non commerciale - Non opere derivate 4.0 Internazionale. 


\section{Joseph Jurt, Flaubert et les arts visuels}

Maria Emanuela Raffi 


\section{NOTIZIA}

JOSEPH JURT, Flaubert et les arts visuels, «Romanistische Zeitschrift für Literaturgeschichte / Cahiers d'Histoire des Littératures Romanes», 35, 2011, pp. 31-48.

Dopo un breve panorama storico sui rapporti 'istituzionali' fra pittura e letteratura fino al xIX secolo, momento in cui le immagini visive si moltiplicano fino alla produzione su scala industriale (litografie e xilografie, riproduzioni nei giornali, fotografie), modificando in parte anche il linguaggio letterario, Joseph Jurt prende specificamente in esame la reazione di Flaubert all'invasione di immagini prodotta dal suo tempo, tenendo conto degli studi già condotti da R. Debray-Genette e da A. Tooke sull'argomento. Ostile alla fotografia, considerata un freddo procedimento meccanico, Flaubert ha sempre rifiutato di far pubblicare le poche immagini concesse a Nadar, Carjat e Du Camp e ha sempre privilegiato la rappresentazione letteraria della realtà, in grado di cogliere colori, movimenti e soprattutto una 'verità' di ordine generale, non superficiale. Contrario all'illustrazione dei suoi testi, con la sola eccezione della riproduzione della vetrata della cattedrale di Rouen in Saint Julien, lo scrittore mostra tuttavia una singolare «acuité visuelle» nei confronti delle opere pittoriche, espressa particolarmente nei confronti del quadro di Breughel La Tentation de Saint Antoine, ma visibile nelle sue opere anche per i quadri di Decamps, Delacroix , Horace Vernet e altri e per le incisioni di Daumier e Gavarni. A questa specifica sensibilità, Jurt aggiunge «les passages picturaux» presenti nell'opera di Flaubert, nei quali lo scrittore evita il linguaggio metaforico dei romantici, producendo una visione dinamica che oppone esplicitamente alla visione immobile-e immobilizzante-della pittura quella spazialmente e temporalmente stratificata della descrizione letteraria, costruita su una sorta di «métonymie filée». A tali passaggi vanno infine aggiunti, come ultima presenza significativa, «les portraits satiriques» costituiti da alcuni personaggi, come Pellerin, pittore fallito dell'Education sentimentale che si trasforma in fotografo. 